\title{
Introgression of Root and Water Use Efficiency Traits Enhances Water Productivity: An Evidence for Physiological Breeding in Rice (Oryza sativa L.)
}

Prathibha M. Dharmappa ${ }^{1}$, Pushpa Doddaraju', Mohankumar V. Malagondanahalli ${ }^{1}$, Raju B. Rangappa ${ }^{1,2}$, N. M. Mallikarjuna', Sowmya H. Rajendrareddy ${ }^{1}$, Ramachandra Ramanjinappa ${ }^{1,3}$, Rajanna P. Mavinahalli", Trichy Ganesh Prasad ${ }^{1}$, Makarla Udayakumar ${ }^{1}$ and Sreeman M. Sheshshayee ${ }^{1 *}$ (D)

\begin{abstract}
Background: Semi-irrigated aerobic cultivation of rice has been suggested as a potential water saving agronomy. However, suitable cultivars are needed in order to sustain yield levels. An introgression of water mining and water use efficiency (WUE) traits is the most appropriate strategy for a comprehensive genetic enhancement to develop such rice cultivars.

Results: We report a novel strategy of phenotyping and marker-assisted backcross breeding to introgress water mining (root) and water use efficiency (WUE) traits into a popular high yielding cultivar, IR-64. Trait donor genotypes for root (AC39020) and WUE (IET-16348) were crossed separately and the resultant $F_{1} s$ were inter-mated to generate double cross $\mathrm{F}_{1} \mathrm{~s}\left(\mathrm{DCF}_{1}\right)$. Progenies of three generations of backcross followed by selfing were charatcerised for target phenotype and genome integration. A set of 260 trait introgressed lines were identified. Root weight and root length of TILs were 53\% and $23.5 \%$ higher, while $\Delta^{13} \mathrm{C}$ was $2.85 \%$ lower indicating a significant increase in WUE over IR-64. Five best TILS selected from $\mathrm{BC}_{3} \mathrm{~F}_{3}$ generation showed $52 \%$ and $63 \%$ increase in yield over IR-64 under 100\% and $60 \% \mathrm{FC}$, respectively. The trait introgressed lines resembled IR64 with more than 97\% of genome recovered with a significant yield advantage under semi-irrigated aerobic conditions The study validated markers identified earlier by association mapping.

Conclusion: Introgression of root and WUE into IR64, resulted in an excellent yield advantage even when cultivated under semi-irrigated aerobic condition. The study provided a proof-of-concept that maintaining leaf turgor and carbon metabolism results in improved adaptation to water limited conditions and sustains productivity. A marker based multiparent backcross breeding is an appropriate approach for trait introgression. The trait introgressed lines developed can be effectively used in future crop improvement programs as donor lines for both root and WUE.
\end{abstract}

Keywords: Aerobic Rice, Roots, Water-use efficiency, Quantitative trait loci, Marker assisted backcross breeding, Carbon isotope discrimination, Phenotyping, Trait introgressed lines, Grain yield

\footnotetext{
* Correspondence: msshesh1@uasbangalore.edu.in

'Department of Crop Physiology, University of Agricultural Sciences, GKVK,

Bengaluru 560065, India

Full list of author information is available at the end of the article
} 


\section{Background}

Rice, that meets over half of the global dietary requirement and $80 \%$ of Asians, is an exhaustive user of fresh water. With increasing water scarcity, cultivating rice in the conventional puddled ecosystem is increasingly becoming uneconomical (Bouman et al. 2005, 2007; Nie et al. 2012). Several agronomic practices such as direct seeding, alternate wetting and drying, and aerobic cultivation have been suggested as water-saving practices (Bouman and Tuong 2001; Atlin et al. 2006; Bouman et al. 2007). The semi-irrigated aerobic cultivation though can potentially save up to $50 \%$ water, a yield penalty of $40 \%$ to $50 \%$ is often reported (De-Datta and Feuer 1975; Widawsky and O'Toole 1990; Fischer et al. 2003; Bouman et al. 2005; Peng et al. 2006; Kreye et al. 2009; Sasaki et al. 2010). This approach involves periodic surface irrigation to bring the soil to $100 \%$ field capacity (FC)) (Bouman and Tuong 2001) which periodically results in the crop experiencing soil moisture stress between episodes of irrigation. Higher VPDs, characteristic to semi-irrigated aerobic environments further reduce carbon assimilation through partial stomatal closure (Carmelita et al. 2011; Turc et al. 2011; Lobell and Gourdji 2012). Periodic soil moisture depletion exacerbates yield loss due to increased spikelet sterility besides decreasing carbon assimilatory capacity. Therefore, it is imperative that suitable genetic enhancement of rice crop must be achieved to harness the water saving advantages of semi-irrigated aerobic cultivation.

Breeding effort to sustain productivity was predominantly achieved through selection for absolute yield under stress (Affholder et al. 2013; Kumar et al. 2014; Dixit et al. 2014). A narrow genetic variability in yield among the high yielding cultivars and a large $\mathrm{G} \times \mathrm{E}$ interaction for yield severely limit further progress in improving yields (Araus et al. 2008; Reynolds and Tuberosa 2008). Thus, a focused trait-based breeding is strongly being professed for a more effective genetic enhancement in rice productivity under aerobic condition (Reynolds and Tuberosa 2008; Reynolds and Langridge 2016; Sheshshayee et al. 2018).

There have been significant progress in recent years in enumerating and deciphering component traits that are essential for improving drought adaptation (Serraj et al. 2011; Vadez et al. 2013; Araus and Cairns 2014). Based on large number of systematic investigations, it is evident that maintenance of tissue turgor through better water uptake, conservation and maintenance of carbon assimilatory capacity even under conditions of decreasing turgor have the greatest relevance for drought adaptation (Blum 2011; Lopes et al. 2011; Bartlett et al. 2012; Osakabe et al. 2014; Meinzer et al. 2014; Sheshshayee et al. 2018).For a comprehensive improvement of drought adaptation, it is desirable that these constitutive traits are introgressed (Blum 2011; Tardieu 2012) onto an elite genetic background.

While the relevance of root traits in water uptake is unequivocally accepted (Gowda et al. 2011; Henry et al. 2011; Kitomi et al. 2015; Price and Tomos 1997; Serraj et al. 2011; Steel et al. 2006, 2013; Uga et al. 2011, 2012, 2013, 2015; White et al. 2015), the relevance of water use efficiency has been debated (Blum 2011; Sheshshayee et al. 2012). We provided convincing experimental evidences demonstrating the relevance of WUE in improving drought adaptation (Sheshshayee et al. 2012). Similar to the observations made by Reynolds and Langridge (2016), we also provided evidences that the greatest impact on drought adaptation is noticed only when relevant traits are introgressed on to a single genetic background (Raju et al. 2014).

Recently, through association genetic approach we identified a few robust markers governing WUE, root and other physiological traits along with specific trait donor genotypes (Raju et al. 2016). IR64, one of the popular Mega varieties cultivated under puddle conditions, is highly sensitive to water deficit conditions. The major goal of the present investigation was to introgress root and WUE traits into the genetic background of IR-64. A novel approach for introgressing specific traits through marker assisted backcross breeding combined with phenotypic selection was deployed.

We demonstrate that the trait introgressed lines exhibit superior productivity even under water limiting semi-irrigated aerobic conditions. To the best of our knowledge, this is the first successful effort for introgressing complex physiological traits for improving drought adaptation in rice, an approach gaining prominence as physiological breeding.

\section{Methods \\ Development of Backcross Progenies}

Extensive phenotypic and molecular characterization of 173 Indica rice (Oryza sativa L.) germplasm for drought adaptive traits led to identification of trait specific SSR markers and trait donor lines, AC-39020 and IET-16348 for root and WUE, respectively (Raju et al. 2016). IR-64, a lowland high yielding rice variety was selected as a recurrent parent to introgress root and WUE traits through marker assisted backcross breeding.

\section{Breeding Strategy Marker Analysis at Early Backcross Generations}

Markers associated with root and WUE identified from association mapping were used in the study. Sixteen markers (12 for root traits and 4 for WUE) associated with traits and 120 non-target markers were used for foreground and background selection, respectively. Details of the SSR markers used for foreground selection 
and background selection are given in Table 1 and Additional file 1: Table S1.

\section{Phenotyping for WUE and Roots at Early Backcross Generations}

Besides molecular characterization of progeny, specific proxies for the root and WUE were also measured at each backcross generation. Carbon isotope discrimination $\left(\Delta^{13} \mathrm{C}\right)$, a well-known proxy for WUE (Farquhar et al. 1989) was measured to assess the differences in WUE. Similarly, a non-invasive approach of measuring leaf temperature using infrared thermometer (SCHEDULER Plant Stress-Monitor, USA) was adopted as an indirect estimate of transpiration and hence root traits at early generations of backcrossing (Anda and Ligetvári 1993). At advanced generations after attaining homozyosity, root traits were measured by growing plants in root structures (see later).

Two crosses were effected separately to introgress root and WUE traits into IR64 (Fig. 1). True $F_{1}$ plants were identified using SSR markers associated with target traits (Table 1). The identified true $\mathrm{F}_{1} \mathrm{~s}$ were inter-mated to develop double-cross $\mathrm{F}_{1} \mathrm{~s}\left(\mathrm{DCF}_{1}\right)$.

At each generation, molecular and phenotypic characterization was performed to identify best trait introgreesed lines with maximum number of target marker loci in heterozygous condition and trait expression using proxies. These best trait introgressed line were backcrossed with IR-64 to generate backcross progenies till $\mathrm{BC}_{3}$ generation. See Fig. 1 for details.

Four best $\mathrm{BC}_{3} \mathrm{~F}_{1}$ plants (foreground selection for the target markers, background selection for maximum recurrent parent genome recovery and the proxy phenotype traits) were selfed to generate $\mathrm{BC}_{3} \mathrm{~F}_{2}$ seeds (more than 10,000). A set of $1440 \mathrm{BC}_{3} \mathrm{~F}_{2}$ plants were taken for phenotyping growth and yield parameters under aerobic field condition. A set of selected 260 promising lines were advanced and the $\mathrm{BC}_{3} \mathrm{~F}_{3}$ lines were phenotyped for root and WUE traits by raising the plants in specially designed root structures (Additional file 1: Figure S1) (Raju et al. 2014, 2016). The same set of $260 \mathrm{BC}_{3} \mathrm{~F}_{3}$ lines were phenotyped for yield and yield attributes under aerobic field condition. Based on field experiments, Five $\mathrm{BC}_{3} \mathrm{~F}_{4}$ lines were selected for assessing the yield performance under aerobic field conditions using a managed drought Environment (MDE) facility.

\section{PCR Conditions for Genotyping}

DNA was extracted from young leaves of two-week-old plants using modified CTAB method (Saghai-Maroof et al. 1984). The DNA fragments were amplified using $30 \mathrm{ng}$ template DNA, $1.5 \mu \mathrm{L}$ PCR buffer (10X), $1.5 \mu \mathrm{L}$ dNTPs (2 $\mathrm{mM}), 1.5 \mu \mathrm{L}$ forward and reverse primer $(5 \mathrm{pmol} / \mu \mathrm{L}), 1 \mathrm{U}$ Taq DNA polymerase and volume made up to $15 \mu \mathrm{L}$ with sterile water. All the amplified products were analysed on microchip based electrophoresis system MultiNA (Shimadzu biotech, Japan) (Mathithumilan et al. 2013).

Table 1 List of markers associated with specific target trait used for Foreground selection

\begin{tabular}{|c|c|c|c|c|c|c|c|c|}
\hline Trait associated & Trait component & Marker & Chr. no & Position on chromosome (cM) & $R^{2}$ & IR-64 & AC-39020 & IET-16348 \\
\hline \multirow[t]{12}{*}{ Root } & RLD & RM80 & 8 & 103.7 & 19.0 & 132 & 143 & 122 \\
\hline & RWT & RM2584 & 8 & 45.8 & 14.5 & 173 & 176 & 247 \\
\hline & RLD & RM1388 & 4 & 77.9 & 17.2 & 245 & 235 & 215 \\
\hline & RLD & RM262 & 2 & 81.1 & 14.5 & 185 & 178 & 170 \\
\hline & $R / S$ & RM239 & 10 & 25.2 & 13.8 & 194 & 198 & 219 \\
\hline & RV & RM3825 & 1 & 143.7 & 13.0 & 163 & 169 & 154 \\
\hline & RV & RM16 & 3 & 131.5 & 10.8 & 186 & 187 & 167 \\
\hline & RL & RM3276 & 4 & 102.4 & 13.3 & 158 & 190 & 169 \\
\hline & RV & RM247 & 12 & 32.3 & 12.1 & 145 & 139 & 166 \\
\hline & RLD & RM167 & 4 & 37.5 & 16.7 & 167 & 129 & 146 \\
\hline & RV & RM4455 & 10 & 21.8 & 20.4 & 221 & 298 & 149 \\
\hline & $R / S$ & RM71 & 2 & 49.8 & 10.1 & 160 & 143 & 168 \\
\hline \multirow[t]{4}{*}{$\Delta^{13} \mathrm{C}$} & $\Delta^{13} \mathrm{C}$ & RM493 & 1 & 79.9 & 14.2 & 260 & 250 & 240 \\
\hline & $\Delta^{13} C$ & RM586 & 6 & 7.4 & 17.4 & 243 & 272 & 278 \\
\hline & $\Delta^{13} C$ & RM149 & 8 & 122.1 & 15.4 & 255 & 264 & 357 \\
\hline & $\Delta^{13} \mathrm{C}$ & RM131 & 4 & 148.8 & 18.3 & 217 & 207 & 223 \\
\hline
\end{tabular}

Note: These markers were discovered by adopting association mapping approach and are reported in Raju et al. (2016). The position of the marker on rice genome was obtained from http://archive.gramene.org/markers/

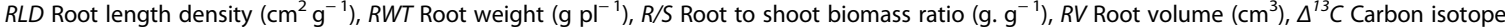
discrimination $(\%)$ 


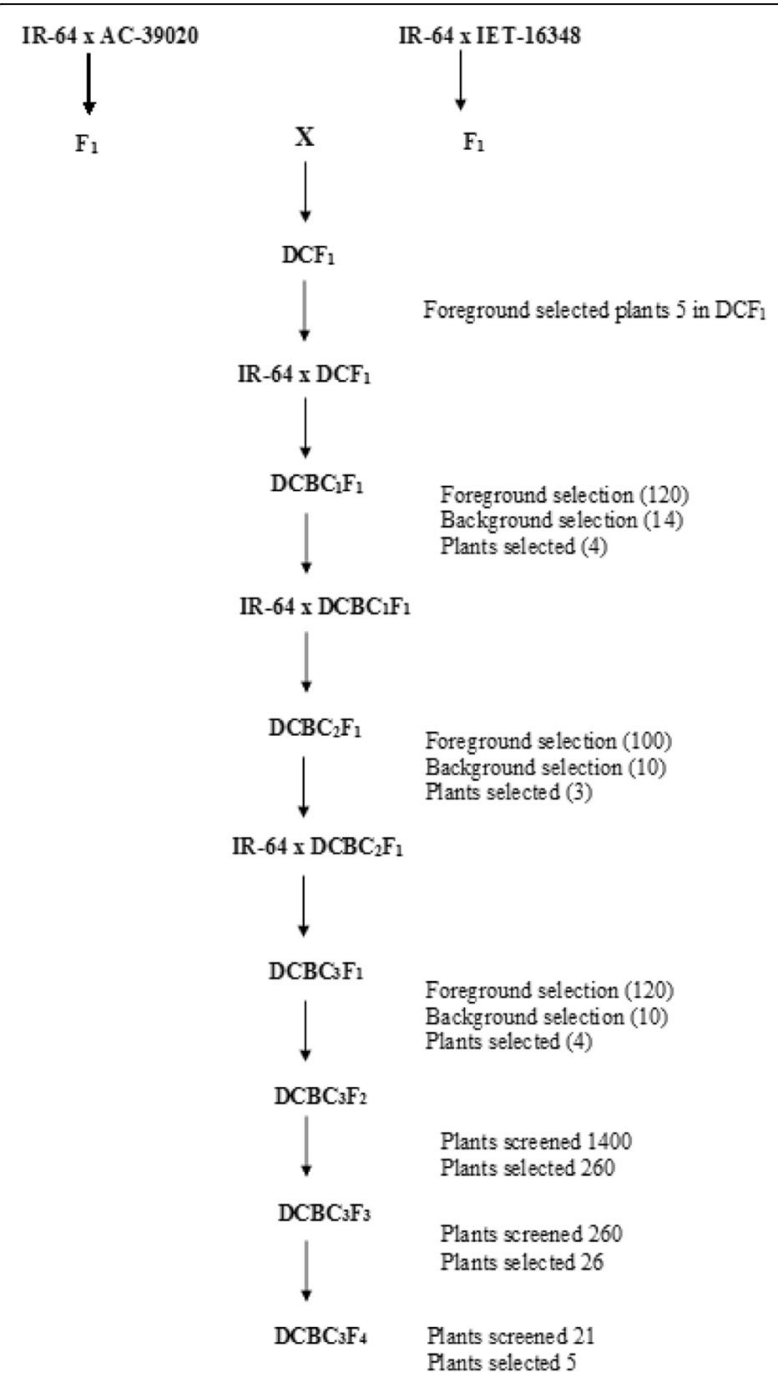

Fig. 1 The scheme of Multi-parent Marker-assisted backcrossing (MABC) to introgress root and WUE traits into IR-64 background. Foot note: Based on phenotypic and molecular diversity AC-39020 and IET-16348 were selected as donor parents for root WUE associated traits. IR-64 was selected as recipient parent because of its drought susceptibility. The donor parents were hybridised with recipient parents separately, to obtain the $F_{1} s$. The resultant $F_{1} s$ were hybridised to get $\mathrm{DCF}_{1}$ s. From this stage, plants were selected and backcrossed with IR-64 till $\mathrm{BC}_{3} \mathrm{~F}_{1}$ stage. Further, selfing was done to identify the trait introgressed lines

\section{Description of Phenotyping Approaches}

The set of 260 most promising trait introgressed $\mathrm{BC}_{3} \mathrm{~F}_{3}$ lines were used for phenotyping water mining traits (roots), yield and yield attributes under semi-irrigated aerobic conditions.

\section{Stable Carbon Isotope Discrimination $\left(\Delta^{13} C\right)$}

Stable carbon isotope composition $\left(\delta^{13} \mathrm{Cp}\right)$ was measured using an isotope ratio mass spectrometer (DeltaV Adv. Thermo Fisher Scientific, Bremen, Germany) interfaced with an elemental analyzer (NA1112, Carlo Erba, Italy) through a continuous flow device (ConFlo III, Thermo Fisher Scientific) installed in the Department of Crop Physiology, UAS, Bangalore, as a national facility. At active tillering stage (45-50 DAS), the second fully expanded leaves were collected from all germplasm separately and dried. The dried leaf samples were homogenized to a fine powder with a ball mill. Three replications from each genotype were used for the measurement of isotope ratios. Carbon isotope discrimination $\Delta^{13} \mathrm{C}$, expressed in per mill (\%), was computed considering the isotopic composition of air $\left(\delta^{13} C_{a}\right)$ as $-8 \%$ relative to Vienna Pee Dee Belemnite (VPDB), as follows (Farquhar et al. 1989):

$$
\Delta^{13} \mathrm{C}=\frac{\left(\delta^{13} \mathrm{C}_{\mathrm{a}}-\delta^{13} \mathrm{C}_{\mathrm{p}}\right)}{\left(1+\delta^{13} \mathrm{Cp} / 1000\right)}
$$

The analytical uncertainty of measurement was determined using a laboratory standard (Potato Starch $\left(C_{3}\right)$, Sigma-Aldrich, $\delta^{13} \mathrm{C}=-26.85 \%$ ) and found to be better than $0.15 \%$. The laboratory standard was calibrated against international standards like ANU Sucrose.

\section{Leaf Temperature as a Proxy for Root Traits in Early Generations}

The leaf temperature of backcross progenies was measured using an infra-red gun (SCHEDULER Plant StressMonitor, USA). The gun was held pointing towards the leaf surface at $25 \mathrm{~cm}$ and the measurements were made at mid-day when there was bright sunlight.

\section{Phenotyping Root Traits in Advanced Generations}

Phenotyping root traits was carried out at the Department of Crop physiology, GKVK, campus of University of Agricultural Sciences, Bengaluru, India located at $12^{\circ}$ $58^{\prime} \mathrm{N}, 77^{\circ} 35^{\prime} \mathrm{E}, 930 \mathrm{~m}$ above mean sea level. Weather data for the GKVK campus during the experimental period are given in Additional file 1: Table S2. Plants were grown in root structures, measuring $150 \mathrm{~cm}$ tall, $300 \mathrm{~cm}$ wide and $1800 \mathrm{~cm}$ long, built using cement bricks. An additional 150 -cm-tall wall was built in the middle of the structure all along the length to make two halves, each $150 \mathrm{~cm}$ wide (Sheshshayee et al. 2011; Raju et al. 2014, 2016). The root structures were filled with red sandy loam soil m1ixed with FYM in 3:1 proportion and compacted to mimic the real field condition. The GKVK campus soil typically holds $22-24 \%$ water (W/W) at $100 \%$ field capacity (FC) with a $\mathrm{pH}$ of 6.5 and bulk density of $1.5 \mathrm{mg} \mathrm{cm}^{-3}$ (Sunil and Shankaralingappa 2014). Twenty-one-day-old seedlings were transplanted in a randomized block design (RBD) with three replications. Each replication comprised of one row with 8 plants at a spacing of $25 \mathrm{~cm}$ between plants and $25 \mathrm{~cm}$ between rows. The advantage of this approach is the maintenance of the same plant population as that in the 
field, thus enabling a realistic phenotypic expression. Standard recommendations of fertilizers $(100: 50: 50 \mathrm{~kg}$ $\mathrm{NPK} / \mathrm{ha}$ ) and other prophylactic measures were taken to raise a healthy crop. The soil moisture status was constantly maintained between 85 and 95\% field capacity (to mimic the real field aerobic situation). Calibrated soil moisture probes (Gopher 9.2, Dataflow Systems Pvt. Ltd., Christchurch, New Zealand) were inserted at various places in the root structures to determine the moisture content at different soil depth and irrigation was scheduled based on the soil moisture data. This method of scheduling irrigation based on soil moisture data ensured maintenance of soil moisture status at a given level despite rains during the experiment. Adequate drainage holes were provided at regular intervals on the walls of the root structure to ensure no stagnation of water. On the 75th day after sowing (DAS), the sidewalls of the root structures were dismantled and roots were extracted carefully with a jet of water to wash away the soil from roots. At the time of harvest, roots were separated from the shoot and several parameters such as root length, root volume (amount of water displaced by fresh roots) and total canopy leaf area were recorded before drying the samples in a hot air oven at $75^{\circ} \mathrm{C}$ until constant weights were reached for recording dry biomass. Leaves were carefully separated from the shoot and roots were cut off and oven dried separately.

\section{Phenotyping Yield Under Aerobic Condition}

Seedling (22 days old) of the selected 260 lines were transplanted in the main field with a spacing of $25 \times 25$ $\mathrm{cm}$ to evaluate their performance under aerobic condition. Surface irrigation was scheduled once in 5 days. At maturity, the entire plant was cut 1 inch above the ground level and the panicles were separated from the stem. The panicles were sundried, whereas the stem samples along with the leaves were oven dried at $75^{\circ} \mathrm{C}$ until constant weights were attained.

\section{Phenotyping Under Managed Drought Environment (MDE) to Evaluate Stress Response}

Five most promising lines from among the 260 TILs were selected for this study. The selected Five TILs along with parental lines were grown under this MDE facility with the spacing of $25 \times 25 \mathrm{~cm}$ with three replications. Two soil moisture regimes viz., wellwatered $(100 \% \mathrm{FC})$ and water-deficit (60\% FC) were maintained by sprinkling $10 \mathrm{~mm}$ of water on alternate days for well-watered and once in three to 5 days for the water-stressed plots for the entire crop growth period. Sprinkler irrigation schedules were determined based on the soil moisture status measured using soil moisture probes (Gopher 9.2, Dataflow Systems Pty Ltd., Christchurch, New Zealand) inserted at several places in the plots of each water regime treatment. Leaf samples were collected at 50 DAS for measuring relative water content (RWC), $\Delta{ }^{13} \mathrm{C}$ specific leaf area (SLA). At final harvest, parameters such as spikelet fertility, grain yield and total above ground biomass were measured.

\section{Relative Water Content (RWC)}

Pieces of a known area of fresh leaves were taken from the first fully expanded leaf from the apex of the plant at $9.00 \mathrm{am}$ and its fresh weight was determined immediately. The leaf bits were immersed in water taken in a beaker and kept for a period of at least $6 \mathrm{~h}$ in dark. The leaf bits were carefully blotted to remove water on the leaf surface and weighed accurately to determine the turgid weight. The leaf bits were then oven dried and the dry weight was recorded. Relative water content was computed as follows (Morgan 1995),

$$
\mathrm{RWC}=\frac{(\mathrm{Fw}-\mathrm{Dw})}{(\mathrm{Tw}-\mathrm{Dw})} \times 100
$$

where: $\mathrm{Fw}=$ Fresh weight; $\mathrm{Tw}=$ Turgid weight; and Dw $=$ Dry weight

\section{Specific Leaf Area (SLA)}

Also referred to as leaf area to mass ratio, is a reflection of leaf spread and hence the surface area for transpiration and photosynthesis. Leaf samples were collected from the second fully expanded leaf from the apex of the plant. Middle $15 \mathrm{~cm}$ long leaf lamina was cut and the average width was determined. The leaf samples were oven dried at $75{ }^{\circ} \mathrm{C}$ and dry weights were recorded after constant weights were attained. SLA was computed as follows (Wilson et al. 1999).

$$
\text { SLA }=\frac{\text { Leaf area }}{\text { Leaf weight }}
$$

\section{Statistical Analysis}

Analysis of Variance was calculated using SPSSv16.0 version. F-test and student's t-test was performed to identify the significant difference among the backcross progenies. Critical Difference (CD) at $P \leq 0.05$ was used to calculate the treatment means. Error bars were used to represent standard error among TILs in all figures. Graphical genotyping of the TILs was performed using the software GGT 2.0.

\section{Results and Discussion}

Saving irrigation water and sustaining productivity that have emerged as major research goals can be achived by improving effective extraction of water and efficient use of water for biomass production. Demonstrating 
that root system is an important trait, notwithstanding, the relevance of water use efficiency (WUE) in improving growth rates has been debated (Blum 2011). We demonstrated that WUE significantly contributes to growth rates in genotypes that used comparable volumes of water (Passioura 2006; Tuberosa 2012; Sheshshayee et al. 2012; Reynolds and Langridge 2016). For a comprehensive improvement in saving water and sustaining productivity, water mining (roots) and WUE need to be introgressed on to a single elite genetic background (Raju et al. 2014; Sheshshayee et al. 2018). Therefore, the major goal of this investigation was to introgress root and WUE traits into IR-64, a high yielding mega variety (Mackill and Khush 2018). We adopted a multi-parent marker assisted backcross breeding strategy to introgress these traits.

\section{Selection of Parents}

While strongly linked DNA markers can accelerate selection of appropriate progeny, identification of robuts trait donor genotypes is equally important.

IR64, developed at the International Rice Research Institute (IRRI), Philippines, is one of the mega varieties of rice cultivated widely in India. The popularity of this variety was primarily due to its high yield potential, better cooking quality/taste and resistance to a few important biotic stresses like leaf blast, bacterial blight and brown plant hopper (Mackill and Khush 2018). But it is well documented that the yield of IR- 64 reduces up to $50 \%$ under water limited conditions (Uga et al. 2013). Hence we selected IR-64 as the recurrent parent to intorgress drought-adaptive traits to improve its productivity under water limited conditions.

In an initial experiment, a panel of Indica rice germplasm were extensively characterized for phenotypic and molecular diversity to identify robustb QTL and trait donor genotypes (Raju et al. 2016). The two donor lines, viz. AC-39020 (for root) and IET-16348 (for WUE) were used for trait introgression through marker assisted backcross breeding into IR-64 background.

The profile of associated polymorphic markers and phenotype of these donor lines in comparison with the recurrent parent are given in Tables 1 and 2 .

\section{Phenotyping for Target Traits Using Proxies}

High throughput phenotyping for root traits and WUE has always been a challenge. Plants ability to discriminate against the heavy isotope of carbon during photosynthesis $\left(\Delta^{13} C\right)$ has been established as a well-accepted surrogate for WUE on a time integrated scale (Farquhar et al. 1989). The relevance of $\Delta^{13} \mathrm{C}$ as a powerful surrogate has been validated in several $C_{3}$ crop species including rice (Impa et al. 2005). While $\Delta^{13} \mathrm{C}$ is a fairly high throughput measurement option, phenotyping for root traits is still challenging. We developed a simple approach of growing plants in raised root structures specially constructed for root phenotyping. However, the disadvantage of this approach is the requirement of destructive sampling and hence will not be suitable for early generation plants.

Transpiration is well known for its role in evaporative cooling besides other advantages in carbon assimilation. At a given VPD, transpiration would be a function of water extraction and hence root traits (Vadez 2014; Reynolds et al. 2016). Hence, canopy temperature is a good proxy for transpiration and hence root traits. We determined the leaf temperatures as a proxy for root traits in early generations while actual root measurements were made in more stabilizing plants (after $\left.\mathrm{BC}_{3} \mathrm{~F}_{3}\right)$.

\section{Trait Introgression and Selection of Introgressed Lines}

IR64 was crossed separately with each of the trait donor genotypes and the resultant $F_{1} s$ were inter-mated to develop double cross $\mathrm{F}_{1}\left(\mathrm{DCF}_{1}\right)$ plants. True $\mathrm{DCF}_{1}$ plants that showed heterozygosity at each of the selected marker loci were identified and used for backcrossing with IR-64. Plants at each of the early backcross generations were phenotyped for $\Delta^{13} \mathrm{C}$ and leaf temperature and genotyped with SSR markers for foreground and background selections. The scheme of crossing and the number of plants selected by markers as well as phenotype for backcrossing is illustrated in Fig. 1.

\section{Phenotypic and Molecular Analysis of Backcross Progenies}

Five true DCF $_{1}$ plants were backcrossed with IR-64 used as the female recurrent parent. This cross resulted in generating $120 \mathrm{BC}_{1} \mathrm{~F}_{1}$ plants which were genotyped for foreground selection using associated SSR markers. A set of $42 \mathrm{BC}_{1} \mathrm{~F}_{1}$ plants with heterozygosity at most of the target loci were phenotyped for $\Delta^{13} \mathrm{C}$ and leaf temperature at grand growth stage. The mean and range for these traits are given in Table 3A. Based on the foreground marker profile and phenotype, $14 \mathrm{BC}_{1} \mathrm{~F}_{1}$ plants were characterised for recurrent parent genome recovery. This led to the identification of four $\mathrm{BC}_{1} \mathrm{~F}_{1}$ plants which were selected for further backcrossing. The results of $\Delta^{13} \mathrm{C}$ and leaf temperature for these four selected lines are presented in Table $3 \mathrm{~B}$. The mean $\Delta^{13} \mathrm{C}$ of the four selected $\mathrm{BC}_{1} \mathrm{~F}_{1}$ plants was $19.45 \%$ and mean leaf temperature was $33.05^{\circ} \mathrm{C}$. The cooler leaves and lower $\Delta^{13} \mathrm{C}$ of the selected introgressed lines compared with IR64 indicate increased WUE and root traits in the progeny.

Backcrossing of these four selected $\mathrm{BC}_{1} \mathrm{~F}_{1}$ plants with IR-64 generated $100 \mathrm{BC}_{2} \mathrm{~F}_{1}$ plants. Based on FGS and phenotyping, 10 plants with maximum number of foreground markers in heterozygous state with lower $\Delta^{13} \mathrm{C}$ 
Table 2 Phenotypic variations and marker polymorphism of the trait donor genotypes in comparison with IR-64

\begin{tabular}{lllllllll}
\hline Parent & RL $(\mathrm{cm})$ & RW $\left(\mathrm{g} \mathrm{pl}^{-1}\right)$ & RV $\left(\mathrm{cm}^{3}\right)$ & $\Delta^{13} \mathrm{C}(\%)$ & TLA $\left(\mathrm{cm}^{2} \mathrm{pl}^{-1}\right)$ & TDM $\left(\mathrm{g} \mathrm{pl}^{-1}\right)$ & DM/LA $\left.(\mathrm{g} \mathrm{m})^{2}\right)$ & $\mathrm{GL} / \mathrm{GW}$ \\
\hline IR-64 & 25.5 & 2.5 & 25.1 & 21.5 & 3543 & 65.61 & 120.76 & 12.11 \\
AC-39020 & 65.4 & 10.4 & 70.3 & 19.5 & 4563 & 120.75 & 188.45 & 1.42 \\
IET-16348 & 35.5 & 5.1 & 50.4 & 18.4 & 3278 & 150.58 & 150.28 & 1.81 \\
\hline
\end{tabular}

Note: $R L$ Root length, $R W$ Root weight, RV Root volume, $\triangle^{13} C$ Carbon isotope discrimination, TLA Total leaf area, TDM Total dry matter, DM/LA Dry matter per unit leaf area, GL/GW Grain length to width ratio

and cooler canopy, were used for background selection. Upon background selection, three lines were further identified. These three lines showed an average of $82.7 \%$ background genome recovery. The theoretically expected background genome recovery at $\mathrm{BC}_{2}$ stage is 87.5\% (Collard et al. 2005). The lower percentage of background genome recovery in our experiment was because of the use of two diverse donor parents for trait introgression. The average $\Delta^{13} \mathrm{C}$ of the selected three $\mathrm{BC}_{2} \mathrm{~F}_{1}$ plants was $18.45 \%$ and the leaf temperature was $32.07^{\circ} \mathrm{C}$, which were significantly lower than IR64 (Table $3 \mathrm{~B}$ ). Generally, $\mathrm{BC}_{2} \mathrm{~F}_{1}$ plants are selfed to achieve homozygosity of the target loci. This strategy works best when only one donor parent is crossed with the recurrent parent. Since the observed average genome recovery was only $82.7 \%$ in our case, the three most promising $\mathrm{BC}_{2} \mathrm{~F}_{1}$ plants namely $32-1,73-3$ and $81-23$ with maximum foreground markers were backcrossed with IR-64 to generate a total of $120 \mathrm{BC}_{3} \mathrm{~F}_{1}$ plants.

These $120 \mathrm{BC}_{3} \mathrm{~F}_{1}$ plants were again genotyped for target loci and phenotyped for $\Delta^{13} \mathrm{C}$ and leaf temperature. Based on foreground selection and phenotyping, 10 $\mathrm{BC}_{3} \mathrm{~F}_{1}$ plants that displayed heterozygosity at ten or more marker loci were further selected for background screening. Four individual plants namely $32-1-34,32-$ $1-40,81-23-27,81-23-31$ representing $>90 \%$ of background genome recovery of IR-64 were selected. The mean $\Delta^{13} \mathrm{C}$ of the selected $\mathrm{BC}_{3} \mathrm{~F}_{1}$ plants was $18.75 \%$ and leaf temperature of $31.85^{\circ} \mathrm{C}$ (Table 3B). Field performance in terms of grain yield was possible to be recorded only from $\mathrm{BC}_{3} \mathrm{~F}_{1}$ generation onwards. The yield of the four selected $\mathrm{BC}_{3} \mathrm{~F}_{1}$ plants was generally higher

Table 3 Morpho-physiological and molecular variations of IR-64 and the backcross progenies at different generations (A) mean and range for the phenotypic value of target traits (B) improvement in traits over IR-64 at each generations, number of markers introgressed and background genome recovery in advanced backcross stages

\begin{tabular}{|c|c|c|c|c|c|c|c|c|c|c|c|}
\hline \multicolumn{12}{|l|}{ (A) } \\
\hline \multirow[t]{2}{*}{ Generation } & \multirow[t]{2}{*}{ Season } & \multirow{2}{*}{\multicolumn{2}{|c|}{ \# of plants }} & \multicolumn{4}{|l|}{$\Delta^{13} \mathrm{C}(\% 0)$} & \multicolumn{4}{|l|}{$\operatorname{LT}\left({ }^{\circ} \mathrm{C}\right)$} \\
\hline & & & & IR-64 & Mean \pm SD & \multicolumn{2}{|l|}{ Range } & IR-64 & Mean \pm SD & \multicolumn{2}{|c|}{ Range } \\
\hline $\mathrm{BC}_{1} \mathrm{~F}_{1} \mathrm{a}$ & June-December,2012 & \multicolumn{2}{|l|}{42} & 21.5 & $21.23 \pm 0.95$ & \multicolumn{2}{|c|}{$17.5-25.5$} & 35.6 & $32.3 \pm 2.04$ & \multicolumn{2}{|c|}{$32.4-36.4$} \\
\hline $\mathrm{BC}_{2} \mathrm{~F}_{1}$ & June-December,2014 & \multicolumn{2}{|l|}{100} & 21.88 & $19.7 \pm 0.87$ & \multicolumn{2}{|c|}{$18-25.3$} & 37.2 & $35.0 \pm 1.87$ & \multicolumn{2}{|c|}{$31.4-36.52$} \\
\hline $\mathrm{BC}_{3} \mathrm{~F}_{1}$ & January-May, 2015 & \multicolumn{2}{|l|}{120} & 22.65 & $18.84 \pm 0.93$ & \multicolumn{2}{|c|}{$15.09-20.62$} & 36.3 & $34.34 \pm 1.73$ & \multicolumn{2}{|c|}{$30.2-36.5$} \\
\hline \multicolumn{12}{|l|}{ (B) } \\
\hline \multirow[t]{2}{*}{ Generation } & Plants selected & \multicolumn{2}{|c|}{ \# of markers in heterozygote condition } & \multicolumn{2}{|c|}{ Genome recovery (\%) } & \multicolumn{2}{|c|}{ Phenotype } & \multicolumn{2}{|c|}{ \% change over IR-64 } & \multicolumn{2}{|c|}{ Significance } \\
\hline & & Roots (12) & $\Delta^{13} \mathrm{C}(4)$ & Expected & Estimated & $\Delta^{13} \mathrm{C}$ & $\mathrm{LT}$ & $\Delta^{13} \mathrm{C}(-\mathrm{ve})$ & $\mathrm{LT}(-\mathrm{ve})$ & $\Delta^{13} \mathrm{C}$ & $\mathrm{LT}$ \\
\hline \multirow[t]{4}{*}{$\mathrm{BC}_{1} \mathrm{~F}_{1}$} & 32 & 12 & 4 & 75.0 & 72.5 & 19.5 & 32.1 & 9.30 & 9.83 & \multirow{4}{*}{\multicolumn{2}{|c|}{ ** }} \\
\hline & 73 & 11 & 3 & 75.0 & 69.7 & 19.1 & 33.5 & 11.16 & 5.90 & & \\
\hline & 81 & 12 & 4 & 75.0 & 70.4 & 19.8 & 32.5 & 7.91 & 8.71 & & \\
\hline & 91 & 11 & 2 & 75.0 & 73.2 & 19.4 & 34.1 & 9.77 & 4.21 & & \\
\hline \multirow[t]{3}{*}{$\mathrm{BC}_{2} \mathrm{~F}_{1}$} & $32-1$ & 12 & 4 & 87.5 & 83.2 & 18.28 & 31.6 & 16.45 & 15.05 & \multirow[t]{3}{*}{$* *$} & ** \\
\hline & $73-3$ & 10 & 3 & 87.5 & 82.8 & 18.65 & 33.2 & 14.76 & 10.75 & & \\
\hline & $81-23$ & 12 & 4 & 87.5 & 82.1 & 18.42 & 31.4 & 15.81 & 15.59 & & \\
\hline \multirow[t]{4}{*}{$\mathrm{BC}_{3} \mathrm{~F}_{1}$} & $32-1-34$ & 11 & 3 & 93.75 & 90.5 & 19.96 & 32.1 & 11.88 & 11.57 & \multirow[t]{4}{*}{$* *$} & ** \\
\hline & $32-1-40$ & 10 & 4 & 93.75 & 90.5 & 18.35 & 31.5 & 18.98 & 13.22 & & \\
\hline & $81-23-27$ & 10 & 3 & 93.75 & 91.5 & 17.82 & 32.7 & 21.32 & 9.92 & & \\
\hline & $81-23-31$ & 10 & 4 & 93.75 & 92.5 & 18.85 & 31.1 & 16.78 & 14.33 & & \\
\hline
\end{tabular}

$\triangle^{13} \mathrm{C}$ Carbon isotope discrimination (\%o), $L T$ Leaf temperature $\left({ }^{\circ} \mathrm{C}\right)$

${ }^{a}$ Since this was an early generation only $42 \mathrm{BC}_{1} \mathrm{~F}_{1}$ plants were phenotyped out of the total $120 \mathrm{BC}_{1} \mathrm{~F}_{1}$ plants generated

${ }^{*}$ and ${ }^{* *}$ denote significance at $5 \%$ and $1 \%$, respectively 
than IR-64 (Additional file 1: Table S3) convincingly demonstrating the importance of introgressing WUE and root traits onto the same genetic background.

We observed that the background genome recovery did not increase as expected as backcrossing advanced. This could have been because of the less number of true double cross $F_{1}$ s selected at the earlier stage. However, a combination of molecular analysis with phenotypic selection would ensure that the minor alleles would not be missed. The markers used for target traits were discovered by association mapping and hence would be single markers that do not represent a genetic interval. Phenotyping for the target traits would be extremely essential to avoid the loss of minor allelic effects while selecting the progeny without interval markers.

The novelty of this approach was the simultaneous screening of the progeny for marker integration and phenotypic improvement. This strategy of backcross breeding provided a very strong validation for the markers identified by association mapping besides accelerating development of TILs in the elite genetic background of IR-64.

The selected $\mathrm{BC}_{3} \mathrm{~F}_{1}$ plants were selfed to generate a large repository of $\mathrm{BC}_{3} \mathrm{~F}_{2}$ seeds. The rationale of the advancement was that we identified four best $\mathrm{BC}_{3} \mathrm{~F}_{1}$ plants with maximum number of foreground markers, highest yield and highest background genome recovery and picked $500 \mathrm{BC}_{3} \mathrm{~F}_{2}$ seeds from each of the selected $\mathrm{BC}_{3} \mathrm{~F}_{1}$ plants for further characterization under semi-irrigated field conditions.

\section{Molecular and Phenotypic Characterization of $\mathrm{BC}_{3} \mathrm{~F}_{2}$}

Markers in $\mathrm{LD}$ with the target traits were used for screening a set of 1440 segregating progenies at $\mathrm{BC}_{3} \mathrm{~F}_{2}$ generation. A presentative gel image derived from MultiNA is given in Additional file 3: Figure S4A. At this stage the selection was performed for homozygosity at each of the target marker locus.

\section{Field Evaluation of $\mathrm{BC}_{3} \mathrm{~F}_{2}$ Plants}

A set of $1440 \mathrm{BC}_{3} \mathrm{~F}_{2}$ plants were selected and raised in field under semi-irrigated aerobic condition. Specific leaf area (SLA) was determined as yet another proxy for WUE (Sheshshayee et al. 2006). SLA was lowest in IET16348, indicating high WUE while it was high for IR-64 (Table 4). The average SLA for the $1440 \mathrm{BC}_{3} \mathrm{~F}_{2}$ plants was $170 \mathrm{~cm}^{2} \mathrm{~g}^{-1}$ which was lower than that of the trait donor parent, IET-16348. The SLA ranged between 111 $\mathrm{cm}^{2} \mathrm{~g}^{-1}$ and $287 \mathrm{~cm}^{2} \mathrm{~g}^{-1}$, skewed towards the trait donor parent type indicating a targeted improvement in WUE. Grain yield and biomass also revealed a skewed distribution, though the traits varied between 4 and $55 \mathrm{~g}$ $\mathrm{pl}^{-1}$ and $12-147 \mathrm{~g} \mathrm{pl}^{-1}$, respectively. The mean grain yield of the $\mathrm{BC}_{3} \mathrm{~F}_{2}$ progenies was significantly higher than IR-64 (Additional file 1: Figure S2). Though favourable alleles of root and WUE were introgressed, there is a possibility where combination of unfavourable alleles may occur. The frequency distribution of grain yield, TDM along with other traits illustrated in Additional file 1: Figure S3.

We suggest that when water acquisition and water use efficiency traits are introgressed, plants can effectively use water for growth. Increase in WUE without a reduction in transpiration is only possible when a genotype has higher photosynthetic capacity (Udayakumar et al. 1998; Sheshshayee et al. 2003, 2012, 2018). A significant increase in DM/LA, an indicator of net assimilation rate among the backcross progenies (Table 4) illustrates the improved carbon assimilation capacity among the TILs. To further verify the performance of TILs, a set of 260 $\mathrm{BC}_{3} \mathrm{~F}_{2}$ lines were selected based on grain yield and TDM. The mean and range for grain yield and TDM of these selected $260 \mathrm{BC}_{3} \mathrm{~F}_{3}$ lines are given in Table 4 .

\section{Molecular and Phenotypic Characterization of $\mathrm{BC}_{3} \mathrm{~F}_{3}$ Lines} The marker profiles of all the 260 lines are given in Additional file 2: Table S4. In advancedbackcross progeny $\left(\mathrm{BC}_{3} \mathrm{~F}_{3}\right)$, homozygosity of the target loci were screened to confirm the donor alleles (Additional file 3: Figure S4B).

To examine the trait introgression and its relevance, two elaborate phenotypic experiments were carried out. Root phenotyping was done in root structure while yield was monitored under aerocbic field conditions in two separate experiments.

\section{Experiment 1: Phenotyping for Root and WUE Traits of $\mathrm{BC}_{3} \mathrm{~F}_{3}$ Lines}

The average root length and root weight of the selected 260 TILs was $33.8 \mathrm{~cm}$ and $4.9 \mathrm{~g} \mathrm{pl}^{-1}$, respectively and the corresponding values for IR- 64 were $26 \mathrm{~cm}$ and $3.2 \mathrm{~g}$ $\mathrm{pl}^{-1}$. A good number of TILs showed higher root length and root weight than IR-64 and the root donor genotype AC-39020 (Table 5, Fig. 2 and Additional file 1: Figure S5). Similarly, the average $\Delta^{13} \mathrm{C}$ of the selected TILs was 19.57 which was significantly lower than that for IR-64 (Table 5 and Additional file 1: Figure S5) A significantly higher TDM of the selected 260 TILs compared with IR-64 emphasized the relevance of introgressing root and WUE traits.

In semi-irrigated aerobic condition, there would be more water in deeper soil profiles and hence extraction through better roots system would be useful. However, the imminent threat of exhausting soil moisture looms with deep rootedness (Farooq et al. 2009). Therefore, improving WUE becomes essential. Despite the theoretical importance of WUE in determining crop growth rates (Passioura, 1986), there has not been any great enthusiasm among the breeders to exploit the observed 
Table 4 Performance of parents and the segregating $\mathrm{BC}_{3} \mathrm{~F}_{2}(n=1440)$ progenies for various morpho-physiological traits under semiirrigated aerobic condition

\begin{tabular}{|c|c|c|c|c|}
\hline Parents/Progenies & SLA & GY & TDM & DM/LA \\
\hline IR-64 & $210.8 \pm 16.5$ & $20.3 \pm 3.2$ & $70 \pm 6.3$ & 116.4 \\
\hline AC-39020 & $196.28 \pm 21.2$ & $16.5 \pm 5.4$ & $103 \pm 8.5$ & 183.3 \\
\hline IET-16348 & $180.9 \pm 14.3$ & $14.6 \pm 3.5$ & $81.5 \pm 5.4$ & 160.5 \\
\hline Mean of $1440 \mathrm{BC}_{3} \mathrm{~F}_{2}$ plants & 170.46 & 35.50 & 74.97 & 145.3 \\
\hline Range & $(111-287)$ & $(4-55.5)$ & $(12-147)$ & $(100-189)$ \\
\hline Selected 260 plants & 204.5 & 44.06 & 103.5 & 154.6 \\
\hline$C D$ & 81.3 & 4.5 & 8.6 & 9.3 \\
\hline CV & 12.4 & 8.6 & 12.3 & 13.4 \\
\hline
\end{tabular}

Note: SLA Specific leaf area $\left(\mathrm{cm}^{2} \mathrm{~g}^{-1}\right), G Y$ Grain yield $\left(\mathrm{g} \mathrm{pl}^{-1}\right), T D M$ Total dry matter $\left(\mathrm{g} \mathrm{pl}^{-1}\right), D M / L A$ Dry matter per unit leaf area $\left(\mathrm{g} \mathrm{m}^{-2}\right)$

genetic variability for crop improvement. Evolutionarily plant maximized WUE predominantly through a reduction in transpiration. Though this water conservation is a useful strategy for survival, reduced transpiration is also associated with a concomitant reduction in $\mathrm{CO}_{2}$ influx for photosynthesis. Therefore, selecting for high WUE often resulted in reduced growth rates (Richards et al. 2002; Blum 2005, Sheshshayee et al. 2003; Condon et al. 2004). On the other hand, it is argued that an effective use of water is more relevant for improving growth rates (Blum 2005). We suggest that an effective use of water is possible when plants extract more water from deeper profiles of soil and uses the water more efficiently for biomass production. When water use is combined with WUE, unproductive water loss can be minimized hence improving water productivity. Therefore, it's quite perceivable that a genotype that possesses high WUE despite deep rootedness will have superior growth rates and biomass accumulation capacity. The 260 TILs with better root and WUE indeed showed significantly higher biomass and net assimilation rate (DM/LA) (Table 5).

Table 5 Variability in root traits and other biometric parameters among parents and $\mathrm{BC}_{3} \mathrm{~F}_{3}$ progenies

\begin{tabular}{lllllllll}
\hline Parents/Progenies & PH & RL & RW & SLA & TLA & $\Delta^{13} \mathrm{C}$ & TDM & DM/LA \\
\hline IR-64 & 80 & 26 & 3.20 & 208 & 3467 & 22.42 & 45.40 & 152.3 \\
AC-39020 & 105 & 41 & 7.40 & 216 & 4732 & 22.31 & 71.10 & 198.4 \\
IET-16348 & 94 & 33 & 3.40 & 188 & 3533 & 19.43 & 56.20 & 165.3 \\
260 lines & 83 & 34 & 4.90 & 202 & 3234 & 19.57 & 59.60 & 176.4 \\
Minimum & 65 & 20 & 1.54 & 182 & 2342 & 16.31 & 40.00 & 80 \\
Maximum & 85 & 70 & 12.2 & 232 & 5343 & 21.56 & 120.00 & 220 \\
CD & 4.6 & 5.8 & 1.90 & 52.16 & 987 & 1.15 & 13.13 & 8.56 \\
CV & 5.4 & 12.3 & 8.60 & 13.5 & 14.5 & 5.40 & 7.60 & 16.6
\end{tabular}

Note: $P H$ Plant height (cm), $R L$ Root length (cm), $R W$ Root weight $\left(\mathrm{g} \mathrm{pl}^{-1}\right), T L A$ Total leaf area $\left(\mathrm{cm}^{2} \mathrm{pl}^{-1}\right)$, SLA Specific leaf area $\left(\mathrm{cm}^{2} \mathrm{~g}^{-1}\right), \Delta^{13} \mathrm{C}$ Carbon isotope discrimination (\%o), TDM Total dry matter $\left(\mathrm{g} \mathrm{pl}^{-1}\right), D M / L A$ Dry matter per unit leaf area $\left(\mathrm{g} \mathrm{m}^{-2}\right)$

\section{Experiment 2- Productivity of $\mathrm{BC}_{3} \mathrm{~F}_{3}$ Lines Under Semi- Irrigated Aerobic Condition}

IR-64 is a widely adapted high yielding mega variety cultivated predominantly under puddle conditions is a drought sensitive cultivar (Serraj et al. 2011). It is well documented that the reduction in yield of IR-64 under water limited conditions is primarily due to increased spikelet sterility, especially when stress occurs during reproductive stage of crop growth. The shallow rootedness of IR-64 is often attributed to reduced water relations of both leaf and spikelets (Kamoshita et al. 2008).

In the present field experiment also IR-64 recorded a mean spikelet fertility of $54 \%$, while the deep rooted donor genotype was significantly higher with $83 \%$ spikelet fertility (Table 6). Average yield of the 260 promising TILs at $\mathrm{BC}_{3} \mathrm{~F}_{3}$ generation was significantly higher $\left(27 \mathrm{~g} \mathrm{pl}^{-1}\right)$ than IR-64 $\left(22 \mathrm{~g} \mathrm{pl}^{-1}\right)$ by over $17 \%$. Though the minimum yield value of some of the TILs was as low as $7.5 \mathrm{~g} \mathrm{pl}^{-1}, 75 \%$ of the TILs recorded more yield than IR-64. This segregation ratio of 1:3 indicates the selection of dominant characters that improved yield among most of the TILs. All the selected TILs had lower $\Delta^{13} \mathrm{C}$ (16 to $21.6 \%$ ) than IR-64 $(22.4 \%$ ) and $83 \%$ of all the TILs recorded higher root biomass than IR-64. The spikelet fertility of TILs ranged between 65 and $95 \%$ which was significantly more than that of IR-64 (Table 6).

\section{Comparative Stress Response of TILs Under Managed Drought Environment}

Aerobic cultivation conditions are characterized by periodic water stress (between irrigation schedules) and a higher VPD during the entire growing season. Under the conditions that favor transpiration, water productivity can only be enhanced when WUE is also increased. Five TILs with high root, low $\Delta^{13} \mathrm{C}$ and similar leaf area were selected from $\mathrm{BC}_{3} \mathrm{~F}_{3}$ to ascertain the field level performance under managed drought environment (MDE) condition. This MDE facility with a mobile rain-out shelter 


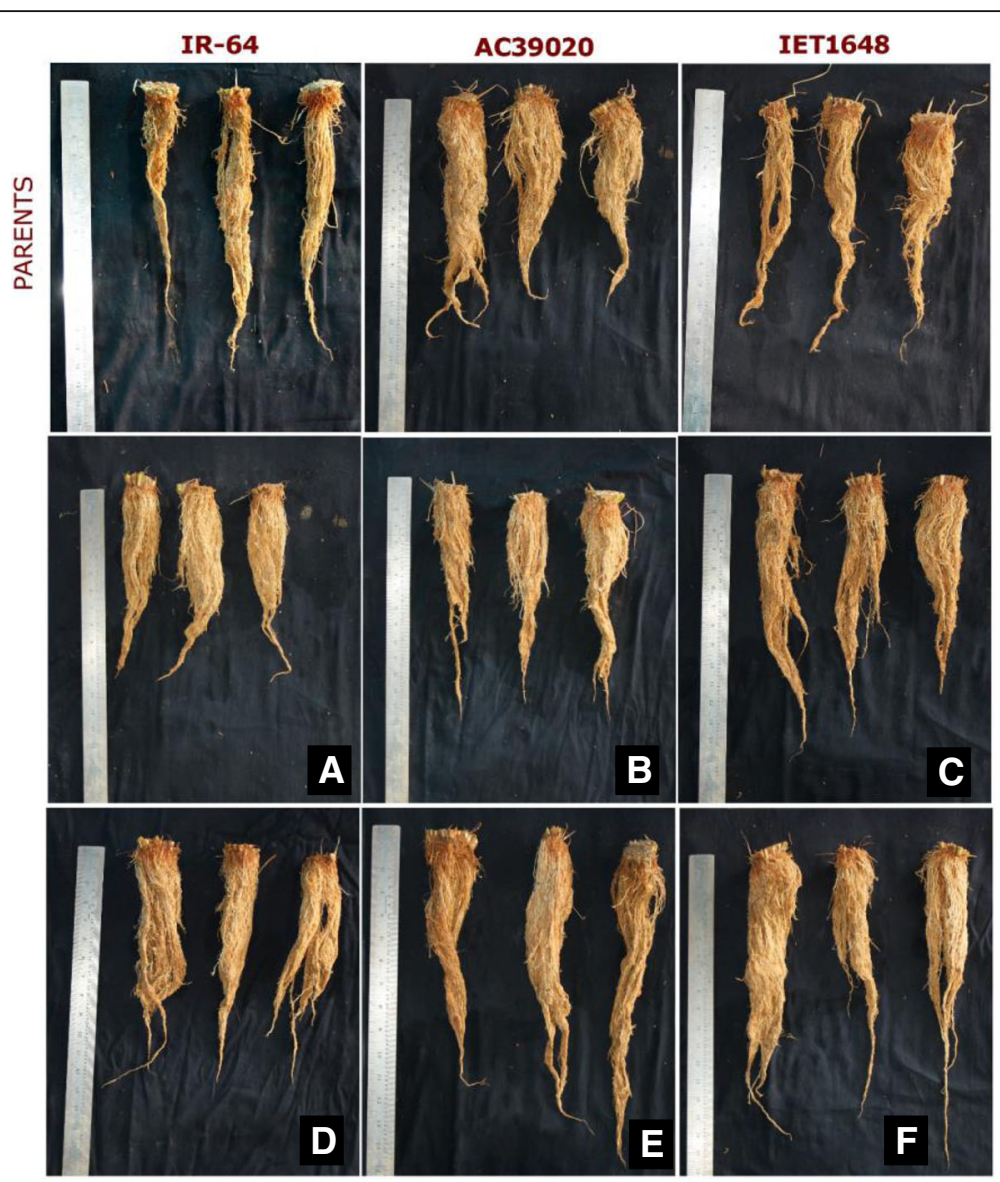

Fig. 2 Improvement in root traits of TILs as compared to parents. a -TIL-32-1-40-84-54, b -32-1-40-24-57, c -32-1-40-78-84, d -81-23-27-378-93, e -81-23-31-75-157, $\mathbf{f}-81-23-31-75-187$ Foot note: Plants were raised in root structure and the roots were harvested at 75DAS. The panel a to $\mathbf{f}$ represent the improved root traits in TILS

Table 6 Variability in yield and yield-related traits among parents and $\mathrm{BC}_{3} \mathrm{~F}_{3}$ progenies for under semi-irrigated aerobic condition

\begin{tabular}{llllllllll}
\hline Parents/Progenies & DFF & PN & \# of S/P & TW & PL & SF & GY & GL & GW \\
\hline IR-64 & 84 & 22 & 123 & 24 & 18 & 54 & 23 & 9.10 & 2.10 \\
AC-39020 & 103 & 11 & 82 & 34 & 17 & 83 & 23 & 6.00 & 3.00 \\
IET-16348 & 95 & 21 & 159 & 27 & 17 & 72 & 26 & 7.60 & 2.20 \\
260 lines & 84 & 23 & 117 & 27 & 18 & 80 & 32 & 8.88 & 2.06 \\
Minimum & 76 & 18 & 97 & 21 & 10 & 65 & 8 & 7.60 & 1.28 \\
Maximum & 95 & 28 & 143 & 29 & 21 & 95 & 50 & 9.77 & 2.41 \\
CD & 6.4 & 4.2 & 7.6 & 3.3 & 3.9 & 12.4 & 6.12 & 0.522 & 0.32 \\
CV & 3.6 & 2.1 & 4.3 & 6.8 & 5.4 & 5.5 & 7.6 & 5.6 & 4.3 \\
\hline
\end{tabular}

Note: DFF Days to $50 \%$ flowering (days), PN Panicle number (\#), \# of S/P Number of spikelets per panicle (\#), TW Test weight $(\mathrm{g}), P L$ Panicle length $(\mathrm{cm})$, SF Spikelet fertility (\%), GY Grain yield ( $\left.\mathrm{g} \mathrm{pl}^{-1}\right)$, GL Grain length (mm), GW Grain width $(\mathrm{mm})$ effectively mimics aerobic field conditions by maintaining specific soil moisture status throughout the crop growth period. The selected five TILs $\left(\mathrm{BC}_{3} \mathrm{~F}_{4}\right.$ lines) were grown in plots of $2 \mathrm{~m}^{2}$ size under two moisture regimes namely, 100\% FC and 60\% FC.

Aerobic cultivation of rice is characterized by surface irrigation once in 5-6 days. In this practice, the soil is never saturated and there is a possibility of water percolating into deeper layers. Thus, the soil progressively dries and an intermittent water limited situation is often created between the episodes of irrigation (Bouman and Tuong 2001) Therefore, the two soil moisture regimes selected in the MDE study represent the entire range of condition that is experienced under aerobic conditions.

Under this condition, we tested the yield performance of the five selected TILs in comparison with IR-64. The mean yield of five TILs under both water regimes was $52 \%$ (100\% FC) and 63\% (60\% FC) higher than IR-64. The RWC of IR-64 and the five TILs was comparable under 100\% FC treatment. Though both IR-64 and the TILs had reduced RWC under water limited condition, 

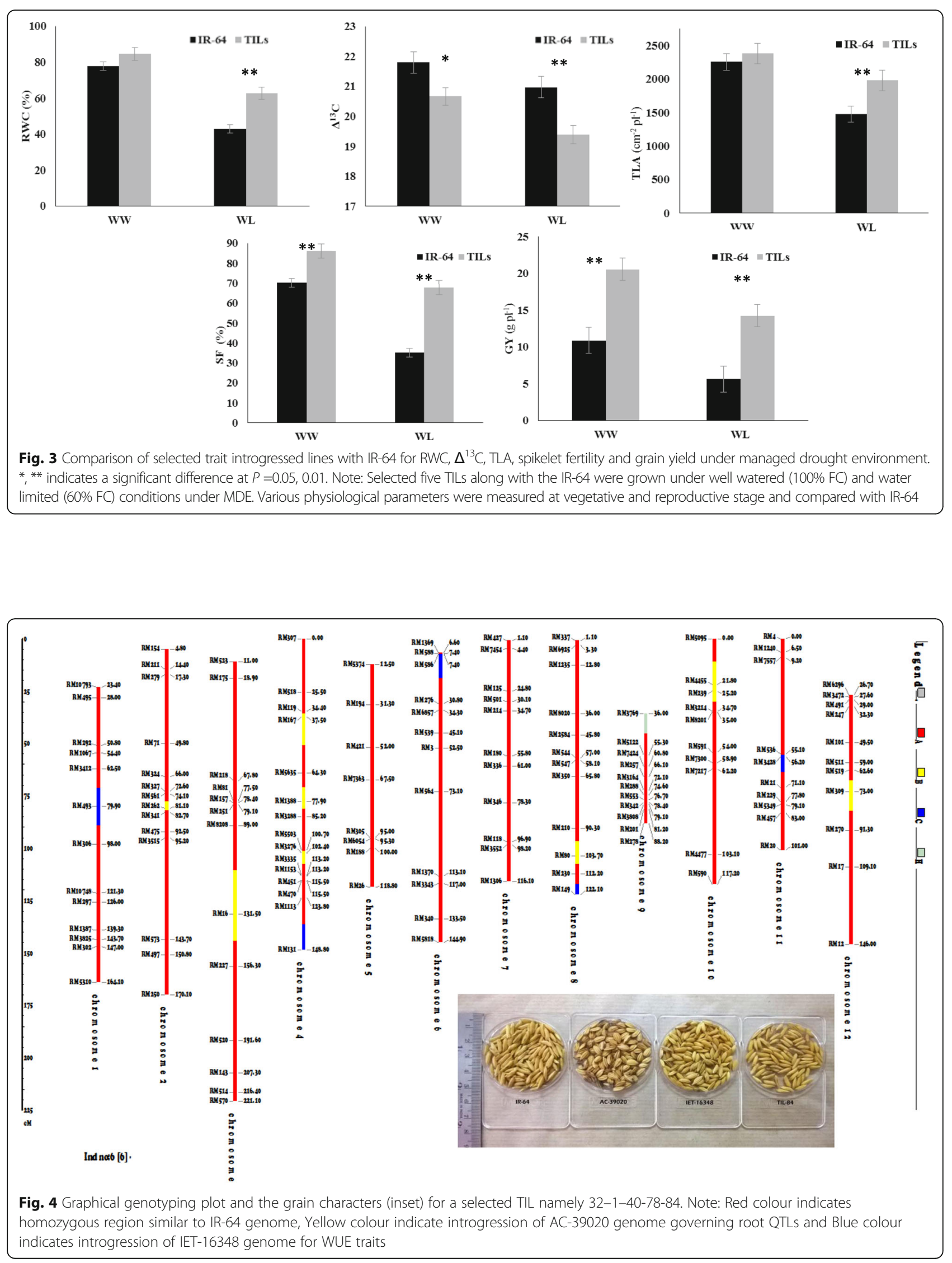
the TILs maintained a significantly higher tissue water status than IR-64 (Fig. 3). The canopies of TILs were significantly cooler compared to IR-64, especially under water limited condition (data not given). Stomatal closure is one of the fastest responses under water limited condition. This often leads to decrease in intercellular $\mathrm{CO}_{2}$ concentration $(\mathrm{Ci})$ and hence a decreased $\Delta^{13} \mathrm{C}$ is often noticed (Hubick et al. 1988). TILs on an average revealed lower $\Delta^{13} \mathrm{C}$ than IR-64 in both $100 \% \mathrm{FC}$ and $60 \%$ FC conditions. Besides stomatal conductance $\left(\mathrm{g}_{\mathrm{s}}\right)$, the carboxylation capacity can also alter $\mathrm{Ci}$ levels and hence $\Delta^{13} \mathrm{C}$. The TILs are characterized by a higher carbon assimilation capacity and hence a lower $\Delta^{13} \mathrm{C}$ under any condition is expected.

Introgression of root and WUE rendered the plants to maintain tissue water relations as well as metabolism under decreased water status. Thus, the spikelet fertility of TILs was significantly higher even under water limited condition and hence had higher grain yield (Fig. 3).

The morphological characters of TILs were highly comparable with IR-64, indicating the recovery of IR-64 characters. As an evidence of the recurrent parent genome recovery, graphical genotyping and grain characteristics of one TIL viz. $32-1-40-78-84$ is given in Fig. 4. The detailed information about the genome recovery from $\mathrm{BC}_{2} \mathrm{~F}_{1}$ till $\mathrm{BC}_{3} \mathrm{~F}_{4}$ for the selected best TILs is given in Additional file 4: Table S5.

The genome integration data along with these morphological similarities with IR-64 emphasizes the recovery of recurrent parent genome with the integration of desirable target traits (Additional file 1: Figure S6). Some of the morpho-physiological characters such as leaf size and grain characters for the parents and the TILs are given in Additional file 1: Table S6.

These results clearly illustrate that introgressing diverse physiological and morphological traits alone can significantly improve productivity under water limited conditions, while saving irrigation water. This work provides a proof of concept that improving physiological traits associated with maintenance of tissue turgor and metabolism is the most appropriate strategy to enhance growth rates and productivity under water limited conditions.

\section{Conclusion}

We provided experimental evidences to prove that introgression of root traits to harness water from deeper soil layers and efficient use of water for biomass production, can substantially increase yield levels under water limiting semi-irrigated aerobic conditions. A novel approach of using multiple trait donor genotypes and selecting promising lines using SSR markers associated with WUE and root traits accelerated trait introgression.. Improvements in root traits and WUE resulted in higher spikelet fertility among the TILs and carbon assimilatory capacity. This resulted in the trait introgressed lines showing more than $30 \%$ increase in productivity under water limiting conditions of aerobic cultivation. With a significantly high level of genome recovery, the TILs can be considered as "improved IR-64" with enhanced productivity and drought adaptability. To our knowledge, this is the first successful report of breeding to improve physiological traits in rice.

\section{Additional files}

Additional file 1: Figure S1. Root phenotyping using root structures. Figure S2. Identification of trait introgressed lines for advancing at $\mathrm{BC}_{3} \mathrm{~F}_{2}$ stage. Figure S3. Frequency distribution of $\mathrm{BC}_{3} \mathrm{~F}_{2}$ population for various morpho-physiological traits under aerobic condition. \# indicates the value for recurrent parent IR-64. Figure S5. Frequency distribution of $\mathrm{BC}_{3} \mathrm{~F}_{3}$ population for various morpho-physiological traits in root structure. Figure S6. Improved phenotype of the selected TILs along with parents. Table S1. Background markers used in the study for reconstructing IR-64 background. Table S2. Differences in weather parameters between experimental locations (Bengaluru and Mandya). Table S3. Improvement of yield and yield-attributes among selected trait introgressed $B C_{3} F_{1}$ progenies. Table S6. Morphophysiological characters of TILs under well-watered and water limited condition along with IR-64. (DOCX 4617 kb)

Additional file 2: Table S4. Foreground genotyping of trait introgressed lines using associated markers for specific target traits. (XLSX 24 kb)

Additional file 3: Figure S4. Representative gel images derived from MultiNA for segregating $B C_{3} F_{2}$ progenies $(A)$ and trait introgressed $B C_{3} F_{3}$ progenies (B) along with parents. (DOCX $365 \mathrm{~kb}$ )

Additional file 4: Table S5. Genotyping of the selected TILs with SSR markers for Background genome recovery and their chromosomal positions. (XLSX $18 \mathrm{~kb}$ )

\section{Abbreviations}

BGS: Background section; DM/LA: Dry matter per unit leaf area; FC: Field capacity; FGS: Foreground selection; MABC: Marker assisted backcross; MDE: Managed drought environment; NAR: Net assimilation rate; QTL: Quantitative trait loci; RWC: Relative water content; SLA: Specific leaf area; TILs: Trait introgressed lines; WUE: Water use efficiency

\section{Acknowledgements}

Authors acknowledge the financial help from DBT Program Support (BT/01/ COE/05/03) and Niche area of Excellence program of ICAR (F.No. 10-(6)/2005 EP\&D). We also thank the DBT-HUB program that supported the fellowship to Prathibha MD. Authors thank all the phenotyping team in UAS (Bangalore) and ZARS Mandya for their support. We wish to place on record the help rendered by Dr. S. Robin, Professor of Genetics and Plant Breeding, Tamil Nadu Agricultural University (TNAU), Coimbatore, India. His untimely demise has left a void in molecular breeding in India.

\section{Funding}

Financial help from DBT Program Support (BT/01/COE/05/03) and Niche area of Excellence program of ICAR (F.No. 10-(6)/2005 EP\&D) was provided to MSS and MUK.

\section{Availability of Data and Materials}

All relevant data have been provided as Tables, Figures with in the text and in the following supplementary data.

\section{Authors' Contributions}

PMD conducted all the experiments and wrote the first draft of the manuscript. PD assisted in genotyping and phenotyping of backcross lines and edited the manuscript. MVM, RBR, SHR, RR all helped in identifying the markers for fore ground selection and edited the manuscript. MNM and RPM, developed the initial Introgressing crosses and assisted in selection of 
true $F_{1}$ s. TGP and MUK provided technical advice during formulation of the program and funded the project partially. MSS conceptualized the project and directed all activities and provided funds for operation and fellowships to PMD. All authors read and approved the final manuscript.

\section{Ethics Approval and Consent to Participate}

Not applicable as no animal experiments were involved in the entire project.

\section{Consent for Publication}

All the authors have given their consent to publish the manuscript.

\section{Competing Interests}

The authors declare that they have no competing interests.

\section{Publisher's Note}

Springer Nature remains neutral with regard to jurisdictional claims in published maps and institutional affiliations.

\section{Author details}

'Department of Crop Physiology, University of Agricultural Sciences, GKVK, Bengaluru 560065, India. ${ }^{2}$ Present address- Department of Agronomy Kansas State University, Kansas, USA. ${ }^{3}$ Present address: Assistant Professor, Department of Biotechnology, Reva University, Bengaluru, India. ${ }^{4}$ Rice Breeder, Zonal Agricultural Research Station, VC Farm, Mandya 571405, India.

\section{Received: 27 July 2018 Accepted: 11 February 2019}

\section{Published online: 07 March 2019}

\section{References}

Affholder FO, Poeydebat C, Corbeels M, Scopel E, Tittonell P (2013) The yield gap of major food crops in family agriculture in the tropics: assessment and analysis through field surveys and modelling. Field Crops Res 143:106-118. https://doi.org/10.1016/j.fcr.2012.10.021

Anda A, Ligetvári $F$ (1993) Potential use of the scheduler plant stress monitor in soybean. Soil Technol 6:137-144. https://doi.org/10.1016/09333630(93)90002-V

Araus JL, Cairns JE (2014) Field high-throughput phenotyping: the new crop breeding frontier. Trends Plant Sci1 9:52-61. https://doi.org/10.1016/j.tplants. 2013.09.008

Araus JL, Slafer GA, Royo C, Serret MD (2008) Breeding for yield potential and stress adaptation in cereals. Crit Rev Plant Sci 27:377-412. https://doi.org/10 1080/07352680802467736

Atlin GN, Lafitte HR, Tao D, Laza M, Amante M, Courtois B (2006) Developing rice cultivars for high-fertility upland systems in the Asian tropics. Field Crops Res 97:43-52. https://doi.org/10.1016/j.fcr.2005.08.014

Bartlett MK, Scoffoni C, Sack L (2012) The determinants of leaf turgor loss point and prediction of drought tolerance of species and biomes: a global meta-analysis. Ecol Lett 15:393-405. https://doi.org/10.1111/j.1461-0248.2012.01751.x

Blum A (2005) Drought resistance, water-use efficiency, and yield potential - Are they compatible, dissonant, or mutually exclusive? Aust J Agric Res 56:11591168. https://doi.org/10.1071/AR05069

Blum A (2011) Plant breeding for water-limited environments. https://doi.org/10. 1007/978-1-4419-7491-4 4

Bouman BAM, Humphreys E, Toung TP, Barker R (2007) Rice and water. Adv Agron 92:187-237. https://doi.org/10.1016/S0065-2113(04)92004-4

Bouman BAM, Peng S, Castaneda AR, Visperas RM (2005) Yield and water use of irrigated tropical aerobic rice systems. Agr Water Manage 74:87-105

Bouman BAM, Tuong TP (2001) Field water management to save water and increase its productivity in irrigated rice. Agr Water Manage 49:11-30. https:// doi.org/10.1016/S0378-3774(00)00128-1

Carmelita M, Alberto R, Wassmann R, Hiranob T, Miyatac A, Hatanob R, Kumara A, Padrea A, Amante M (2011) Comparisons of energy balance and evapotranspiration between flooded and aerobic rice fields in the Philippines. Agr Water Manage 98:1417-1430. https://doi.org/10.1016/j.agwat. 2011.04.011

Collard BCY, Jahufer MZZ, Brouwer JB, Pang ECK (2005) An introduction to markers, quantitative trait loci (QTL) mapping and marker-assisted selection for crop improvement: the basic concepts. Euphytica 142:169-196. https:// doi.org/10.1007/s10681-005-1681-5

Condon AG, Richards R, Rebetzke GJ, Farquhar GD (2004) Breeding for high wateruse efficiency. J Exp Bot 55:2447-2460. https://doi.org/10.1093/jxb/erh277
De-Datta SK, Feuer R (1975) Soils on which upland rice is grown in: major research in upland rice. IRRI, Los Baños, pp 27-39

Dixit S, Singh A, Kumar A (2014) Rice breeding for high grain yield under drought: a strategic solution to a complex problem. Int J Agron 2014:1-15. https://doi.org/10.1155/2014/863683

Faroog M, Wahid A, Kobayashi N, Fujita D, Basra SMA (2009) Plant drought stress: effects, mechanisms and management. Agron Sustain Dev 29:185-212. https://doi.org/10.1051/agro:2008021

Farquhar GD, Ehleringer JR, Hubick KT (1989) Carbon isotope discrimination and photosynthesis. Annu Rev Plant Phys 40:503-537. https://doi.org/10.1146/ annurev.pp.40.060189.002443

Fischer KS, Lafitte R, Fukai S, Atlin G, Hardy B, editors (2003) Breeding rice for drought-prone environments. Los Baños (Philippines): International Rice Research Institute. p. 98.

Gowda VRP, Henry A, Yamauchi A, Shashidhar HE, Serraj R (2011) Root biology and genetic improvement for drought avoidance in rice. Field Crop Res 122: 1-13. https://doi.org/10.1016/j.fcr.2011.03.001

Henry A, Gowda VRP, Torres RO, McNally KL, Serraj R (2011) Variation in root system architecture and drought response in rice (Oryza sativa): phenotyping of the Oryza SNP panel in rainfed lowland fields. Field Crops Res 120:205214. https://doi.org/10.1016/j.fcr.2010.10.003

Hubick KT., Shorter R, Farquhar GD. (1988). Heritability and genotype $\times$ environment interactions of carbon isotope discrimination and transpiration efficiency in peanut. Aust. J. Plant Physiol. 15: 799-813.

Impa SM, Nadaradjan S, Boominathan P, Shashidhar G, Bindumadhava H, Sheshshayee MS (2005) Carbon isotope discrimination accurately reflects variability in WUE measured at a whole plant level in rice. Crop Sci 45:25172522. https://doi.org/10.2135/cropsci2005.0119

Kamoshita A, Babu RC, Boopathi NM, Fukai S (2008) Phenotypic and genotypic analysis of drought-resistance traits for development of rice cultivars adapted to rainfed environments. Field Crops Res 109:1-23. https://doi.org/10.1016/j. fcr.2008.06.010

Kitomi Y, Kanno N, Kawai S, Mizubayashi T, Fukuoka S, Uga Y (2015) QTLs underlying natural variation of root growth angle among rice cultivars with the same functional allele of DEEPER ROOTING 1. Rice 8:16

Kreye C, Bouman BAM, Reversat G, Fernandez L, Vera Cruz C, Elazegui F, Faronilo JE, Llorca $L$ (2009) Biotic and abiotic causes of yield failure in tropical aerobic rice. Field Crops Res 112:97-106. https://doi.org/10.1016/j.fcr.2009.02.005

Kumar A, Dixit S, Ram T, Yadaw RB, Mishra KK, Mandal NP (2014) Breeding highyielding drought-tolerant rice: genetic variations and conventional and molecular approaches. J Exp Bot 65:6265-6278. https://doi.org/10.1093/jxb/eru363

Lobell DB, Gourdji SM (2012) The influence of climate change on global crop productivity. Plant Physiol 160:1686-1697. https://doi.org/10.1104/pp.112.208298

Lopes MS, Araus JL, Van Heerden PDR, Foyer CH (2011) Enhancing drought tolerance in C4 crops. J Exp Bot 62:3135-3153. https:/doi.org/10.1093/jxb/err105

Mackill DJ, Khush GS (2018) IR64: a high-quality and high-yielding mega variety. Rice 11:18. https://doi.org/10.1186/s12284-018-0208-3

Mathithumilan B, Kadam NN, Jyoti B, Sowmya HR, Mahadeva A, Madhura JN, Udayakumar M, Paramjit K, Sheshshayee MS (2013) Development and characterization of microsatellite markers for Morus spp. and assessment of their transferability to other closely related species. BMC Plant Biol 13:14712229. https://doi.org/10.1186/1471-2229-13-194

Meinzer FC, Woodruff DR, Marias DE, McCulloh KA, Sevanto S (2014) Dynamics of leaf water relations components in co-occurring iso and anisohydric conifer species. Plant Cell Environ 37:2577-2586. https://doi.org/10.1111/pce.12327

Morgan JM (1995) Growth and yield of wheat lines with differing osmoregulative capacity at high soil water deficit in seasons of varying evaporative demand. Field Crops Res 40:143-152. https://doi.org/10.1016/0378-4290(94)00100-Q

Nie L, Peng S, Chen M (2012) Aerobic rice for water-saving agriculture. Agron Sustain Dev 32:411-418. https://doi.org/10.1007/s13593-011-0055-8

Osakabe Y, Osakabe K, Shinozaki K, Son PL (2014) Response of plants to water stress. Front Plant Sci 5:1-11. https://doi.org/10.3389/fpls.2014.00086

Passioura J (2006) Increasing crop productivity when water is scarce - from breeding to field management. Agr Water Manage 80:176-196. https://doi. org/10.1016/j.agwat.2005.07.012

Passioura JB (1986) Resistance to Drought and Salinity: Avenues for Improvement. Aust. J of Plant Physio. 13(1): 191-201.

Peng S, Bouman BAM, Visperas RM, Castañeda A, Nie L, Park HK (2006) Comparison between aerobic and flooded rice in the tropics: agronomic performance in an eight-season experiment. Field Crops Res 96:252-259. https://doi.org/10.1016/j.fcr.2005.07.007 
Price AH, Tomos AD (1997) Genetic dissection of root growth in rice (Oryza sativa L.). II: mapping quantitative trait loci using molecular markers. Theor App Genet 95:143-152

Raju BR, Mohankumar MV, Sumanth KK, Rajanna MP, Udayakumar M, Prasad TG, Sheshshayee MS (2016) Discovery of QTLs for water mining and water use efficiency traits in rice under water-limited condition through association mapping. Mol Breed 36:1-16. https://doi.org/10.1007/s1103

Raju BR, Narayanaswamy B, Mohankumar MV, Sumanth KK, Rajanna MP, Mohanraju B, Udayakumar M, Sheshshayee MS (2014) Root traits and cellular level tolerance hold the key in maintaining higher spikelet fertility of rice under water limited conditions. Funct Plant Biol 49:930-939. https://doi.org/ 10.13140/RG.2.1.4994.4089

Reynolds M, Langridge P (2016) Physiological breeding. Curr Opin Plant Biol 31: 162-171. https://doi.org/10.1016/j.pbi.2016.04.005

Reynolds M, Tuberosa R (2008) Translational research impacting on crop productivity in drought-prone environments. Curr Opin Plant Biol 11:171179. https://doi.org/10.1016/j.pbi.2008.02.005

Reynolds MP, Quilligan E, Aggarwal PK, Bansal KC, Cavalieri AJ, Chapman SC, Chapotin SM, Datta SK, Duveiller E, Gill KS, Jagadish KSV, Joshi AK, Koehler AK, Kosina P, Krishnan S, Lafitte R, Mahala RS, Muthurajan R, Paterson AH, Prasanna BM, Rakshit S, Rosegrant MW, Sharma I, Singh RP, Sivasankar S, Vadez V, Valluru R, Prasad PW, Yadav OM (2016) An integrated approach to maintaining cereal productivity under climate change. Glob Food Sec 8 : 2211-9124. https://doi.org/10.1016/j.gfs.2016.02.002

Richards RR, Rebetzke GJ, Condon AGA, Herwaarden FV, Herwaarden VA (2002) Breeding opportunities for increasing the efficiency of water use and crop yield in temperate cereals. Crop Sci 42:111-121. https://doi.org/10.2135/cropsci2002.1110

Saghai-Maroof MA, Solima KM, Jorgenson RA, Allard RW (1984) Ribosomal DNA spacer-length polymorphisms in barley: Mendelian inheritance, chromosomal location, and population dynamics. PNAS 81:8014-8018

Sasaki Y, Hosen Y, Peng S, Nie L, Agbisit R, Fernandez L, Bouman BAM (2010) Do abiotic factors cause a gradual yield decline under continuous aerobic rice cultivation? A pot experiment with affected field soils do abiotic factors cause a gradual yield decline under continuous aerobic rice cultivation ? A pot experiment with affected field soils. Soil Sci Plant Nutr 56:476-482. https://doi.org/10.1111/j.1747-0765.2010.00482.x

Serraj R, McNally KL, Slamet-Loedin I, Kohli A, Haefele SM, Atlin G, Kumar A (2011) Drought resistance improvement in Rice: an integrated genetic and resource management strategy. Plant Prod Sci 14:1-14. https://doi.org/10.1626/pps.14.1

Sheshshayee MS, Bindumadhava H, Rachaputi NR, Prasad TG, Udayakumar M, Wright GC, Nigam SN (2006) Leaf chlorophyll concentration relates to transpiration efficiency in peanut. Ann Appl Biol 148:7-15. https://doi.org/10. 1111/j.1744-7348.2005.00033.x

Sheshshayee MS, Bindumadhava H, Shankar AG, Prasad TG, Udayakumar M (2003) Breeding strategies to exploit water use efficiency for crop improvement. J Plant Biol 30:253-268

Sheshshayee MS, Ehab AK, Rohini S, Namita S, Mohanraju B, Nataraja KN, Prasad TG, Udayakumar M (2011) Phenotyping for root traits and their improvement through biotechnological approaches to sustaining crop productivity In Oliveira AC, Varshney R (eds) Root Genomics. Springer-Verlag, Berlin Heidelberg, 2011, p 205-232.

Sheshshayee MS, Mohankumar MV, Raju BR, Pratibha MD, Rajanna MP, Mohan Raju B, Udayakumar M (2012) Enhancing water use efficiency besides effective use of water is a potential strategy in developing rice cultivars suitable for semi-irrigated aerobic cultivation. In: Muralidharan K, Siddiq EA (eds) International dialogue on perception and prospects of designer rice. Society for Advancement of Rice Research, Directorate of Rice Research, Hyderabad, pp 261-272

Sheshshayee MS, Preethi V, Rohini S, Sowmya R, Smitharani A, Pooja B, Prathibha D, Raju S (2018) Introgression of physiological traits for a comprehensive improvement of drought adaptation in crop plants. Front Chem 6. https:// doi.org/10.3389/fchem.2018.00092

Steel KA, Price AH, Shashidhar HE, Witcombe JR (2006) Marker assisted selection to introgress rice QTLs controlling root traits into an Indian upland rice variety. Theor Appl Genet 112:208-221

Steel KA, Price AH, Witcombe JR, Shreshtha R, Singh BN, Gibbons JM, Virk DS (2013) QTLs associated with root traits increase yield in upland rice when transferred through marker assisted selection. Theor Appl Genet 126:101-108

Sunil CM, Shankaralingappa BC (2014) Rooting behaviour of aerobic rice under integrated package of agro-techniques. Asian J Agric Res 8:105-113. https:// doi.org/10.3923/ajar.2014.105.113
Tardieu F (2012) Any trait or trait- related allele can confer drought tolerance: just design the right drought scenario. Exp Bot 63:25-31. https://doi.org/10. 1093/jxb/err269

Tuberosa (2012) Phenotyping for drought tolerance of crops in the genomics era. Front Physiol 3:1-26. https://doi.org/10.3389/fphys.2012.00347

Turc O, Freixes S, Piques M, Muller B, Pantin F, Ge M, Gibon Y (2011) Water deficits uncouple growth from photosynthesis, increase $C$ content, and modify the relationships between $C$ and growth in sink organs. J Exp Bot 62: 1715-1729. https://doi.org/10.1093/jxb/erq438

Udayakumar M, Sheshshayee MS, Nataraj KN, Bindumadhava H, Devendra R, Aftab H, Prasad TG (1998) Why breeding for water use efficiency has not been successful? An analysis and alternate approach to exploit this trait for crop improvement. Cur Sci 74:994-1000

Uga Y, Hanzawa E, Nagai S, Sasaki K, Yano M, Sato T (2012) Identification of aSOR1, a major rice QTL involved in soil-surface rooting in paddy fields. Theor Appl Genet 124:75-86

Uga Y, Kitomi Y, Yamamoto E, Kanno N, Kawai S, Mizubayashi T, Fukuoka S (2015) A QTL for root growth angle on rice chromosome 7 is involved in the genetic pathway of DEEPER ROOTING 1. Rice 8:8

Uga Y, Okuno K, Yano M (2011) Dro 1, a major QTL involved in deep rooting of rice under upland field conditions. J Exp Bot 62:485-2494

Uga Y, Sugimoto K, Ogawa S, Rane J, Ishitani M, Hara N, Kitomi Y, Inukai Y, Ono K, Kanno N, Inoue H, Takehisa H, Motoyama R, Nagamura Y, Wu J, Matsumoto T, Takai T, Okuno K, Yano M (2013) Control of root system architecture by DEEPER ROOTING 1 increases rice yield under drought conditions. Nature Genet 45:1097-1102. https://doi.org/10.1038/ng.2725

Vadez V (2014) Root hydraulics: The forgotten side of roots in drought adaptation. Field Crop Res 165:15-24. https://doi.org/10.1016/j.fcr.2014.03.017

Vadez V, Kholova J, Zaman-Allah M, Belko N (2013) Water: the most important molecular component of water stress tolerance research. Funct Plant Biol 40: 1310-1322. https://doi.org/10.1071/FP13149

White CA, Sylvester-bradley R, Berry PM (2015) Root length densities of UK wheat and oilseed rape crops with implications for water capture and yield. J Exp Bot 66:2293-2303. https://doi.org/10.1093/jxb/erv077

Widawsky DA, OToole JC (1990) Prioritizing the rice biotechnology research agenda for eastern. Indian Rockeffeller Foundation, New York, p 86

Wilson P, Thompson K, Hodgson J (1999) Specific leaf area and leaf dry matter content as alternative predictors of plant strategies. New Phytol 143:155-162. https://doi.org/10.1046/j.1469-8137.1999.00427

\section{Submit your manuscript to a SpringerOpen ${ }^{\circ}$ journal and benefit from:}

- Convenient online submission

- Rigorous peer review

- Open access: articles freely available online

High visibility within the field

- Retaining the copyright to your article

Submit your next manuscript at $\boldsymbol{\nabla}$ springeropen.com 